\title{
Methicillin Resistant Staphylococcus aureus (MRSA) in Patients of Community Based Medical College Hospital, Mymensingh, Bangladesh
}

\author{
Khalid Hussain ${ }^{1}$, Marzia Rahman ${ }^{1,}$, K. H. M. Nazmul Hussain Nazir ${ }^{1}$, Hasibur Rahman ${ }^{2}$, \\ Abul Khair ${ }^{3}$ \\ ${ }^{1}$ Department of Microbiology and Hygiene, Faculty of Veterinary Science, Bangladesh Agricultural University, Mymensingh, Bangladesh \\ ${ }^{2}$ Department of Skin \& VD, Community Based Medical College, Bangladesh, Mymensingh, Bangladesh \\ ${ }^{3}$ Department of Medicine, Faculty of Veterinary Science, Bangladesh Agricultural University, Mymensingh, Bangladesh
}

Email address:

marzia_micro@bau.edu.bd (M. Rahman),nazir@bau.edu.bd (K. H. M. N. H. Nazir)

${ }^{*}$ Corresponding author

To cite this article:

Khalid Hussain, Marzia Rahman, K. H. M. Nazmul Hussain Nazir, Hasibur Rahman, Abul Khair. Methicillin Resistant Staphylococcus aureus (MRSA) in Patients of Community Based Medical College Hospital, Mymensingh, Bangladesh. American Journal of Biomedical and Life Sciences. Vol. 4, No. 3, 2016, pp. 26-29. doi: 10.11648/j.ajbls.20160403.11

Received: March 17, 2016; Accepted: March 28, 2016; Published: April 21, 2016

\begin{abstract}
The rapid rise in resistance of Staphylococcus aureus to various antimicrobial agents is now a growing concern. The objectives of this study were to investigate the frequency of Methicillin Resistant $S$. aureus (MRSA) in different cases of infection, and to determine the pattern of antimicrobial susceptibility among the $S$. aureus originated from human in Mymensingh, Bangladesh. Covering a period of five months during July 2014 to November 2014, a total of 65 samples comprises of pus, wounds, eye lesions, burns were collected from the Community Based Medical College Hospital (CBMCH), Mymensingh, Bangladesh, and the samples were processed at the Department of Microbiology and Hygiene, Bangladesh Agricultural University (BAU), Mymensingh-2202. Among the 65 samples, 20\% ( $\mathrm{n}=13 / 65)$ were confirmed as $S$. aureus on the basis of colony morphology, staining characteristics, biochemical properties, and Polymerase Chain Reaction (PCR) by amplification of nuc gene (amplicon size 279-bp). Among these $13 \mathrm{~S}$. aureus isolates, 15.38\% (n=2/13) were found to be resistant to Methicillin which was confirmed by antibiotic disk sensitivity test and PCR by amplifying MRSA specific mecA gene (amplicon size 533-bp). The antibiotic disk sensitivity test indicated that the MRSA isolates were completely (100\%) resistant to Penicillin and Erythromycin. The MRSA represents a major challenge for treatment in hospital due to the emergence and spread of antibiotic resistant isolates among susceptible individual.
\end{abstract}

Keywords: nuc Gene, mecA Gene, MRSA, Human, Vancomycin

\section{Introduction}

Staphylococcus aureus, a Gram-positive coccus, is a member of the Firmicutes, and is frequently found in the human respiratory tract and on the skin [1]. Methicillin was one of most common types of antibiotics used to treat $S$. aureus infections. Methicillin belongs to a comprehensive class of antimicrobials, the $\beta$-lactam antimicrobials or $\beta$ lactams. The mode of action is inhibition of bacterial cell wall biosynthesis. The $1^{\text {st }}$ Methicillin Resistant $S$. aureus reported in UK just 2 years after the introduction of Methicillin in 1959
[2]. MRSA are often described as community associated or healthcare associated. The MRSA is only susceptible to Vancomycin but it has a carcinogenic effect.

\section{Materials and Methods}

\subsection{Sample Collection}

A total of 65 Samples (Pus, Burn, Wound, Eye lesion) were collected from Community Based Medical College Hospital, Bangladesh (CBMCB) during the period of July 2014 to November 2014 [3, 4]. The collected samples were inoculated 
into nutrient broth (Merck Specialties Private Limited) and incubated at $37^{\circ} \mathrm{C}$ for 3-4 hours followed by inoculation onto $5 \%$ sheep blood agar media and incubated at $37^{\circ} \mathrm{C}$ for overnight. The plates showed $\beta$-hemolysis was suspected as $S$. aureus. Pure culture of $S$. aureus was obtained by repeated sub-culturing onto blood agar media [5].

\subsection{Gram Staining}

Gram's stain was performed in order to observe the morphology of bacteria under light microscope, as per the method described by Jahan et al. [6].

\subsection{Culture in Selective Media}

Suspected $S$. aureus colonies were inoculated onto Mannitol Salt Agar (MSA) media to observe the colony characteristics $[7,8,9]$.

\subsection{Biochemical Tests}

\subsubsection{Catalase Test}

This test was carried out to differentiate the Staphylococci from non-catalase producing Streptococci. The test was done according to the procedure described by Zarzour and Belle [10] and Jahan et al. [6].

\subsubsection{Coagulase Test (Slide Method)}

This test was carried out to distinguish between strains of Staphylococci. For the coagulase test, rabbit plasma was used in this study. The test was done as per the procedure described by Zarzour and Belle [10] and Jahan et al. [6].

\subsection{PCR Amplification of S. aureus Specific nuc Gene}

The suspected $S$. aureus was confirmed by PCR using specific nuc gene primers (Table 1) [11]

\subsection{Extraction of DNA by Boiling Method}

A single colony of $S$. aureus was taken in $200 \mu \mathrm{L}$ of DW in eppendorf tube, mixed well and then boiling for $10 \mathrm{~min}$. After boiling, the tubes were immediately placed on ice for cold shock for 10 minutes followed by centrifugation at $10,000 \mathrm{rpm}$ for $10 \mathrm{~min}$ at $4^{\circ} \mathrm{C}$. The supernatant was collected which was further used as template DNA.

\subsection{Detection of MRSA Specific mecA Gene by PCR}

The suspected Methicillin resistant $S$. aureus was confirmed by PCR using MRSA specific mecA gene, with an expected protocol size $533 \mathrm{bp}$. The DNA of $S$. aureus which showed resistant to Oxacillin in the disk diffusion method was taken for the detection of mecA gene by PCR [11]. For this purpose, mecA gene Forward primer and Reverse primer were used that mentioned in Table 1.

\subsection{PCR Reaction Mixture and Condition}

Each $25 \mu \mathrm{L}$ reaction mixture consists of $5 \mu \mathrm{L}$ genomic DNA, $12.5 \mu \mathrm{L}$ PCR master mixture (Promega, USA), $2 \mu \mathrm{L}$ primer $(1 \mu \mathrm{L}$ forward and $1 \mu \mathrm{L}$ reverse primer) with the final volume adjusted to $25 \mu \mathrm{L}$ with $5.5 \mu \mathrm{L}$ of nuclease free water.

Amplification was done by initial denaturation at $95^{\circ} \mathrm{C}$ for $5 \mathrm{~min}$, followed by 30 cycles of denaturation at $95^{\circ} \mathrm{C}$ for 1 min, anneling temperature of primers was $55^{\circ} \mathrm{C}$ for $45 \mathrm{sec}$ and extension at $72^{\circ} \mathrm{C}$ for $1 \mathrm{~min}$. The final extension was conducted at $72^{\circ} \mathrm{C}$ for $10 \mathrm{~min}[11]$.

\subsection{Agarose Gel Electrophoresis of PCR Product}

The amplified PCR products were resolved by electrophoresis in $2 \%$ agarose gel at $100-\mathrm{V}$ for 30 minutes, stained with ethidium bromide and finally visualized under UV trans-illuminator [11].

Table 1. Primers used in PCR for nuc gene and mecA gene.

\begin{tabular}{|c|c|c|c|}
\hline Primers & Primer sequence $\left(5^{\prime}-3^{\prime}\right)$ & Product size (bp) & Reference \\
\hline $\begin{array}{l}n u c \mathrm{~F} \\
n u c \mathrm{R}\end{array}$ & $\begin{array}{l}\text { 5'-GCG ATT GAT GGT } \\
\text { GAT ACG GTD-3' } \\
\text { 5'-AGC CAA GCC TTG } \\
\text { ACG AAC TAA AGC-3' }\end{array}$ & 279 & {$[12]$} \\
\hline $\begin{array}{l}\text { mec } \mathrm{A} / \mathrm{F} \\
\text { mec } \mathrm{A} / \mathrm{R}\end{array}$ & $\begin{array}{l}\text { 5'-AAA ATC GAT GGT } \\
\text { AAA GGT TGGC-3' } \\
\text { 5'-AGT TCT GGC ACT } \\
\text { ACC GGA TTT TGC-3' }\end{array}$ & 533 & {$[12]$} \\
\hline
\end{tabular}

\subsection{Antimicrobial Susceptibility Testing}

Antibiotic susceptibility test for $S$. aureus isolates was determined by using the disk diffusion $[10,13]$. This test was applied on Muller-Hinton agar media. Cell suspension was prepared in sterile saline to match $0.5 \mathrm{McF}$ arland turbidity standards.

Then sterile cotton swab was dipped into the bacterial suspension and excess fluid was removed by rotate pressing with the inner wall of the suspension tube. The bacteria from the swab were inoculated onto the Muller-Hinton surface, rotating the plate three times at 60 degrees. After drying, the antibiotic disks (Penicillin, Neomycin, Oxacillin, Erythromycin, Vancomycin \& Ciprofloxacin) were placed on the plates.

The plates were incubated in an inverted position overnight at $35^{\circ} \mathrm{C}$. The diameter was measured for each zone of inhibition that appears around the disk. The results were recorded in millimeters. Inhibition zone diameters were compared to the reference list of the manufacturer.

\section{Results and Discussion}

Methicillin resistant $S$. aureus (MRSA) has emerged worldwide as a significant public health problem both in human and animals. $S$. aureus is an important pathogen causing infections in skin and soft tissue as well as food poisoning too. To treat $S$. aureus related infections, it is important to have adequate information and understanding the trends of antibiotic resistance patterns of those respective bacteria.

The clinical samples $(n=65)$ were collected from both sexes and prevalence was found more in female $(55 \%)$ as 
compared to males $(45 \%)$. Out of the 65 samples, $S$. aureus could be isolated from $20 \%(\mathrm{n}=13 / 65)$ samples, and mecA was detected in $15.38 \%(n=2 / 13)$ isolates. In Gram's staining method, it showed smooth, convex, approximately $1 \mathrm{~mm}$ in diameter, grape-like clusters when viewed under light microscope, as reported by Tanzin et al. [11]. It has large, round, golden-yellow colonies, with $\beta$-hemolysis on blood agar plates (Figure 1 and 2), as reported by Kenneth [14] and Stavropoulos et al. [15].

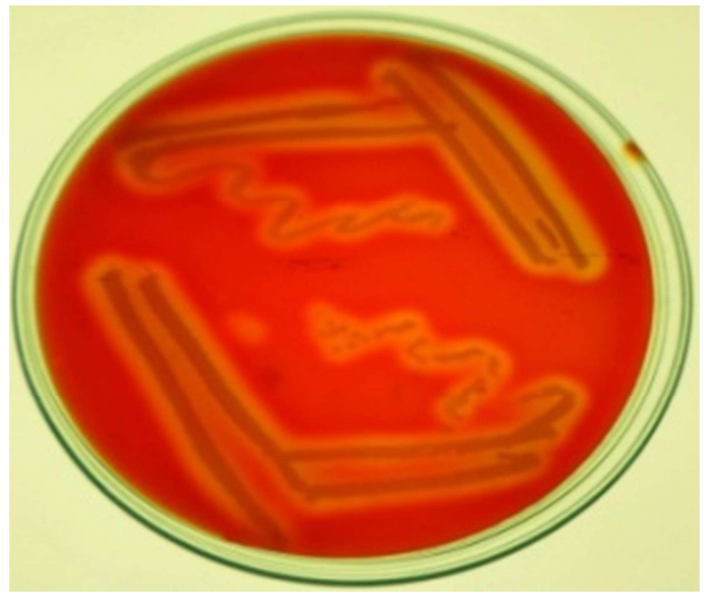

Figure 1. $\beta$-hemolysis produced by the pure culture of Staphylococcus aureus onto $5 \%$ sheep blood agar.

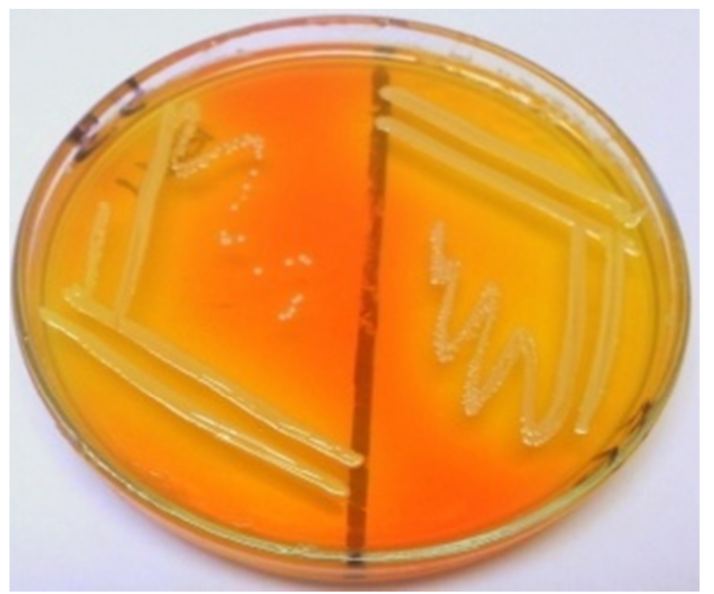

Figure 2. Fermentation of MSA by Staphylococcus aureus indicated by formation of yellowish colony.

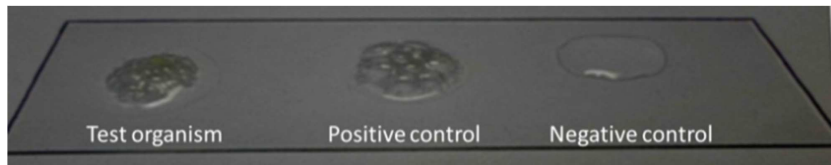

Figure 3. Catalase test (slide test). The positive result is indicated by formation of bubble due to release of oxidation of $\mathrm{H}_{2} \mathrm{O}_{2}$ by catalase enzyme.

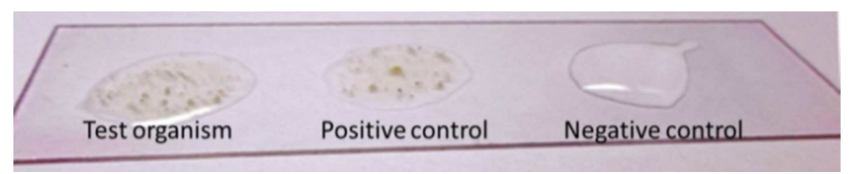

Figure 4. Result of coagulase test (slide test). Positive result is indicated by curd like clotting of plasma by coagulase positive $S$. aureus.

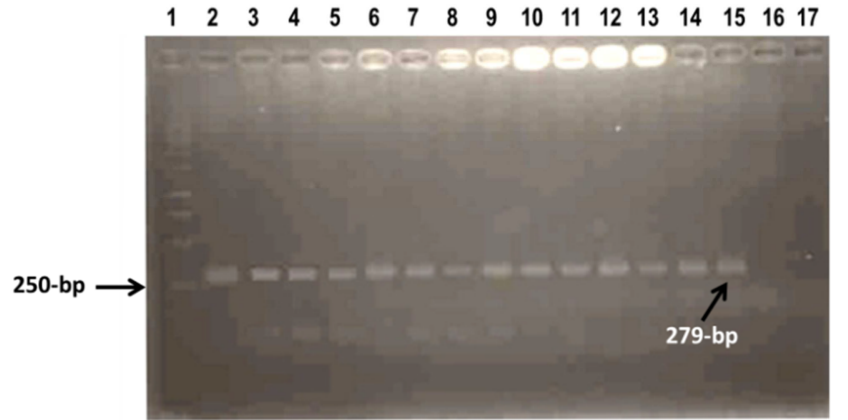

Figure 5. Results of PCR of S. aureus specific nuc gene (size=279 bp). Here Lane 1: $100 \mathrm{bp}$ ladder, 2-14: positive samples amplified nuc gene, L-15: positive control, L-16: negative control, L-17: negative result of test samples.

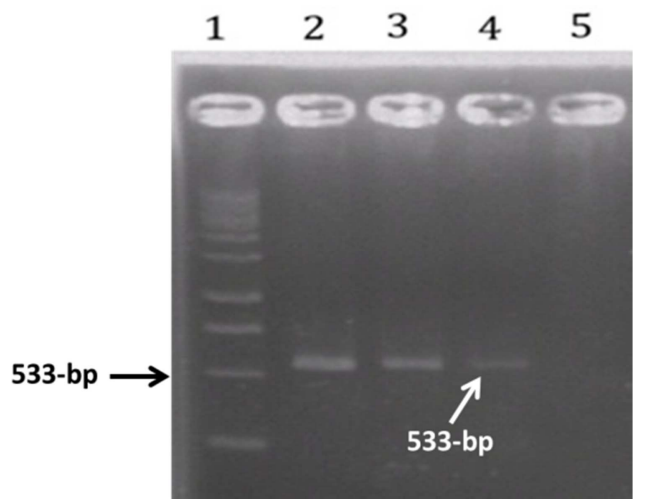

Figure 6. Amplification of mecA gene (size $=533-b p)$ from $S$. aureus $(1=100$ bp ladder, 2,3 =Amplified mecA gene of $S$. aureus, 4=Positive control, 5= Negative control).

All 13 isolates were found both catalase and coagulase positive (Figure 3 and 4). In antimicrobial susceptibility test, both the MRSA strains were resistant to Oxacillin, Erythromycin, Neomycin, Penicillin G and intermediate resistant to Ciprofloxacin. The isolates were sensitive to Vancomycin which is nearly similar to the findings of Anupurba et al. [16], Rajaduraipandi et al. [17], Parveen et al. [18] and Tanzin et al. [11].

PCR based molecular detection was performed to identify the $S$. aureus and MRSA. Amplification of nuc gene by PCR was used for the rapid identification of $S$. aureus. All the 13 isolates were confirmed as $S$. aureus by PCR (Figure 5). After the confirmation of $S$. aureus, amplification of $m e c A$ gene confirmed that 2 isolates were MRSA (Figure 6). The overall prevalence of MRSA was found as $15.38 \%$ $(n=2 / 13)$. This result is lower than the study of [19] who detected 25\% MRSA from human. This might be due to the variation in host and immune status of the host.

\section{Conclusion}

The high level of multiple drug resistance shown by the MRSA isolates in this study is of great concern. All the MRSA isolates showed resistance to at least 4 antibiotics, indicating the presence of strong selective pressure from antibiotics use for human patients. Using methicillin disk diffusion method for detection of MRSA has the same 
sensitivity and specificity as PCR assay. The prevalence of MRSA among the $S$. aureus isolates in Bangladesh is $15.38 \%$, which is slightly lower than that reported on previous study in Bangladesh. The prevalence of MRSA differs throughout the country. It depends on several factors such as indiscriminate use of antibiotics without sensitivity pattern of the infected organisms. For that reason, commensal organisms such as CNS acquired resistance to methicillin which may transfer to pathogenic $S$. aureus. On the other hand, hospital environment may play an important role to spread the infectious agents due to over-crowding of patients and attendants and unhygienic environment.

\section{References}

[1] Donlan, R. M. Costerton, J. W. (2002). Biofilms: survival mechanisms of clinically relevant microorganisms. Clin. Microbiol. Rev. 15: 167-193.

[2] Jevons, M. P. (1961). Cebinin-resistant Staphylococci. Bangladesh Med. J. 1: 124-125.

[3] Islam, M. J. Uddin, M. S. Nasrin, M. S. Nazir, K. H. M. N. H. Rahman, M. T. Alam, M. M. (2007a). Prevalence of enterotoxigenic and toxic shock syndrome toxin-1 producing coagulase positive Staphylococcus aureus in human and their characterization. Bangladesh J. Vet. Med. 5: 115-119.

[4] Islam, M. J. Uddin, M. S. Islam, M. A. Nazir, K. H. M. N. H. Rahman, M. T. Alam, M. M. (2007b). Detection and characterization of coagulase-positive Staphylococcus aureus of bovine origin producing enterotoxins and toxic shock syndrome toxin-1. Bangladesh Vet. 24: 27-33.

[5] Begum, H. A. Uddin, M. S. Islam, M. J. Nazir, K. H. M. N. H. Islam, M. A. Rahman, M. T. (2007). Detection of biofilm producing coagulase positive Staphylococcus aureus from bovine mastitis, their pigment production, hemolytic activity and antibiotic sensitivity pattern. J. Bangladesh Soc. Agric. Sci. Technol. 4: 97-100.

[6] Jahan, M. Rahman, M. Parvej, M. S. Chowdhury, S. M. Z. H. Haque, M. E. Talukder, M. A. K. Ahmed, S. (2015). Isolation and characterization of Staphylococcus aureus from raw cow milk in Bangladesh. J. Adv. Vet. Anim. Res. 2: 49-55.

[7] Chandrasekaran, D. Venkatesan, P. Tirumurugaan, K. G. Gowri, B. Subapriya, S. Thirunavukkarasu, S. (2014). Subacute mastitis associated with Methicillin Resistant Staphylococcus aureus in a cow: A case report. J. Adv. Vet. Anim. Res. 1: 235-237.
[8] Sarker, M. S. Bupasha, Z. B. Rahman, M. M. Akter, S. Mannan, A. Ahaduzzaman, M. (2015). Surgical management of unilateral gangrenous mastitis in a doe: A case report. $J$. Adv. Vet. Anim. Res. 2: 232-235.

[9] Abdelkhalek, A. Elsherbini, M. Eletriby, D. Sadak, A. (2016). Quality assessment of imported powder milk at Mansoura city, Egypt. J. Adv. Vet. Anim. Res. 3: 75-78.

[10] Zarzour, J. Belle, E. A. (1978). Evaluation of three test procedures for identification of Staphylococcus aureus from clinical sources. J. Clin. Microbiol. 7: 133-136.

[11] Tanzin, T. Nazir, K. H. M. N. H. Zahan, M. N. Parvej, M. S. Zesmin, K. Rahman, M. T. (2016). Antibiotic resistance profile of bacteria isolated from raw milk samples of cattle and buffaloes. J. Adv. Vet. Anim. Res. 3: 62-67.

[12] Dewanand, R. K. Yuvaraj, S. Sukhadeo, B. B. (2007). PCRbased detection of genes encoding virulence determinants in Staphylococcus aureus from bovine subclinical mastitis cases. J. Vet. Sci. 8: 151-154.

[13] Roy, S. R. Rahman, M. B. Hassan, J. Nazir, K. H. M. N. H. (2012). Isolation and identification of bacterial flora from internal organs of broiler and their antibiogram studies. Microbes Health, 1: 72-75.

[14] Kenneth, T. (2005). Text book of Bacteriology. http://www.textbookofbacteriology.net/. (Accessed on June, 2006).

[15] Stavropoulos, D. N. Hornby, A. S. (2008). Oxford EnglishGreek Learner's Dictionary. GN Stavropoulos (ed.). Oxford. Oxford University Press. pp. 207.

[16] Anupurba, S. Sen, M. R. Nath, G. Sharma, B. M. Gulati, A. K. Mohapatra, T. M. (2003). Prevalence of methicillin resistant Staphylococcus aureus in a tertiary referral hospital in eastern Uttar Pradesh. Indian J. Med. Microbiol. 21: 49-51.

[17] Rajaduraipandi, K. Mani, K. R. Panneerselvam, K. Mani, M. Bhaskar, M. Manikandan, P. (2006). Prevalence and antimicrobial susceptibility pattern of methicillin resistant Staphylococcus aureus: A multicentre study. Indian J. Med. Microbiol. 24: 34-8.

[18] Parveen, S. Jyothsna, K. (2011). Methicillin Resistance among Isolates of Staphylococcus aureus. Ann. Biolog. Res. 2: 57-61.

[19] Islam, M. A. Alam, M. M. Uddin, M. S. Kobayashi1, N. Ahmed, M. U. (2011). Detection of methicillin resistant Staphlococcus aureus (MRSA) from animal and human origin in Bangladesh by polymerase chain reaction. Bangladesh $J$. Vet. Med. 9: 161-166. 